\title{
A EDUCAÇÃO DE JOVENS E ADULTOS: DESAFIOS DE UMA PRÁTICA LIBERTADORA E REFLEXIVA
}

\section{ARTIGO ORIGINAL}

VIEIRA, Benedito Wagner ${ }^{1}$

VIEIRA, Benedito Wagner. A educação de jovens e adultos: desafios de uma prática libertadora e reflexiva. Revista Científica Multidisciplinar Núcleo do Conhecimento. Ano 06, Ed. 06, Vol. 12, pp. 72-79. Junho de 2021. ISSN: 2448-0959, Link de acesso: https://www.nucleodoconhecimento.com.br/educacao/libertadora-ereflexiva, DOI: 10.32749/nucleodoconhecimento.com.br/educacao/libertadora-ereflexiva

\section{RESUMO}

Como é conhecida, a Educação de Jovens e Adultos (EJA) é um resgate social, uma dívida da sociedade para aquela população marginalizada e excluída do processo educacional. Porém, atualmente, a EJA tem apresentado contextos diversificados no decorrer do curso, isso em decorrência da falta de políticas públicas voltadas principalmente para esta modalidade de ensino. Então, o presente artigo visa melhorar a compreensão e o esclarecimento de alguns pontos relevantes da EJA, apresentando um pouco da relação desta modalidade de ensino numa perspectiva libertadora e reflexiva cuja finalidade é mostrar como a Educação de Jovens e Adultos é percorrida no Brasil, seus desafios e conquistas. Este trabalho se baseia, principalmente, nos livros de Paulo Freire e Miguel Arroyo, por meio de uma pesquisa bibliográfica, tendo uma abordagem crítica e atual dessa temática. Diante disso, pode-se concluir que o processo de ensino e aprendizagem da EJA precisa ser construtivo, capaz de superar as metodologias dos livros didáticos tradicionais que, muitas vezes, pautam-se

\footnotetext{
${ }^{1}$ Pós-graduação e graduação.
}

RC: 89108

Disponível em: https://www.nucleodoconhecimento.com.br/educacao/libertadora-e-reflexiva 
apenas na reprodução de conteúdos. Faz-se necessário a implementação de políticas capazes de resgatar esses alunos muitas vezes evadidos das escolas públicas voltadas para o ensino da EJA.

Palavras-chave: EJA, Cidadania, Liberdade, Escola, Reflexão.

\section{INTRODUÇÃO}

O presente artigo tenta esclarecer um pouco mais sobre a Educação de Jovens e Adultos (EJA), indagando sobre possíveis perspectivas da relação do educando com o saber. Desta forma, veremos um pouco mais a relação da EJA numa perspectiva libertadora e reflexiva cuja finalidade é repensar sobre como esta modalidade de ensino é percorrida no Brasil, seus desafios e conquistas diante da atual conjuntura.

Pensando nesta perspectiva, a pedagogia libertadora é capaz de trazer grandes contribuições na Educação de Jovens e Adultos já que se trata de uma educação com características e necessidades específicas. Na EJA, encontramos alunos que buscam uma segunda oportunidade e vivenciam diversos desafios e a pedagogia libertadora é capaz de atuar revelando que, para que haja uma mudança, é necessária a participação de todos.

Percebemos que a Educação de Jovens e Adultos continua com muitos desafios pela frente, com perspectivas desafiadoras dentro do contexto atual. Para que possamos mudar isto, é preciso pensar a EJA como uma modalidade de ensino mais flexível, uma vez que esses estudantes são, em sua maioria, adultos e precisam ser olhados com maior atenção.

RC: 89108

Disponível em: https://www.nucleodoconhecimento.com.br/educacao/libertadora-e-reflexiva 


\section{OS DESAFIOS DA EDUCAÇÃO DE JOVENS E ADULTOS NA SOCIEDADE CONTEMPORÂNEA}

A Educação de Jovens e Adultos é uma modalidade de ensino destinada às pessoas que não tiveram acesso ou não puderam dar continuidade ao Ensino Fundamental e Médio na faixa etária correspondente. Hoje, embora o Brasil ainda tenha aproximadamente 13 milhões de pessoas não alfabetizadas, podemos perceber que os sistemas de ensino têm oferecido maiores oportunidades educacionais. Sendo assim, essas pessoas que na idade adequada foram privadas, por diversos motivos, dos saberes formais instituídos pela escola, passam a ter seu direito à educação assistido e garantido.

Segundo Gadotti e Romão (2011), muitas vezes os termos educação de adultos, educação popular, educação não formal e educação comunitária são utilizados como sinônimos embora não sejam. As expressões educação de adultos e educação não formal fazem parte de uma mesma área disciplinar, teórica e prática da educação. Entretanto, temos visto a popularização do termo educação de adultos, principalmente em organizações internacionais como a UNESCO, para referir-se a uma área especializada da educação. Os Estados Unidos têm utilizado a educação não formal como referência à educação de adultos desenvolvida nos países do Terceiro Mundo e que geralmente está vinculada a projetos de educação comunitária. E o termo educação de adultos, nos Estados Unidos, é reservado para a educação não formal que é aplicada em nível local no país.

A história nos mostra, por exemplo, que os analfabetos eram proibidos de exercer o direito de votar por não pertencerem ao mundo das letras, por serem vistos como "incapazes" de exercer sua cidadania e democracia. Consequentemente, não participavam de decisões importantes para a construção da história de seu próprio país.

RC: 89108

Disponível em: https://www.nucleodoconhecimento.com.br/educacao/libertadora-e-reflexiva 
Parte dos alunos da EJA (agricultores, pedreiros, auxiliares de serviços, vendedores, empregadas domésticas, babás, entre outros) trabalha durante o dia e estuda à noite. Devido à intensa jornada de trabalho, o cansaço pode ser um agravante para o fracasso ou evasão escolar, além de muitos serem novamente excluídos do processo educacional. Nesse sentido, há uma maior exigência no que se refere ao comprometimento do professor no planejamento da aula. Por isso, é importante que as atividades sejam significativas e estejam direcionadas para as necessidades dos alunos, pois a maioria encontra-se com uma grande bagagem de vida.

Um dos desafios para o professor da EJA é fazer uma ponte entre vivências dos educandos e saberes escolares. Essa ligação permite que novos conhecimentos frutifiquem e que o sujeito conhecedor renasça com uma nova postura e um novo modo de atribuir sentido para suas aprendizagens.

Percebemos que o aluno da EJA apresenta níveis e ritmos de aprendizagem peculiares, bem como experiências, crenças e valores organizados ao longo de sua vida. Essas particularidades devem ser respeitadas a fim de garantir uma melhor qualidade no processo de ensino e aprendizagem, possibilitando um maior tempo de permanência na escola, visto que um de seus maiores problemas atualmente é a evasão. Não bastam políticas públicas de inclusão, precisa-se de muito mais que isso: despertar nos jovens e adultos o gosto pelo ato de aprender e saber.

Desta forma, percebemos que há enormes desafios a serem enfrentados pela EJA. A formação de professores que tenha ênfase nessa modalidade de ensino é um deles. Outro desafio está relacionado ao desenvolvimento profissional. A precariedade das condições de trabalho limita muito a ação do professor, que, em grande parte das vezes, não escolheu ensinar para esses alunos. Quase sempre a atribuição do professor da EJA não se dá por opção político-pedagógica, mas por imposição de carga horária de trabalho ou de outros fatores.

RC: 89108

Disponível em: https://www.nucleodoconhecimento.com.br/educacao/libertadora-e-reflexiva 
Arroyo (2017) compara os estudantes da EJA a passageiros do fim do dia ou do início do dia, que se deslocam pela cidade ou pelos campos, nesta ida e volta do trabalho à EJA, numa luta de deslocamento como classe, gênero e raça. E a EJA torna-se o "espaço-tempo", da mesma forma que os movimentos sociais, o trabalho, a fila, a estação, o ônibus. Assim, "A identidade da educação de pessoas jovens e adultas vem dessa coexistência, encontro, confluência dessas identidades coletivas" (ARROYO, 2017, p. 24).

Veremos a seguir como a EJA pode se tornar uma educação a favor da liberdade dos educandos como cidadãos, da inclusão social e transformação em busca de um futuro melhor. Tudo isso, segundo os postulados da Pedagogia Libertadora de Paulo Freire.

\section{A PEDAGOGIA LIBERTADORA E SUAS CONTRIBUIÇÕES NO CONTEXTO DA EJA}

A Educação de Jovens e Adultos é parte integrante do projeto sociopolítico global da luta popular na sociedade de classes. É parte do processo global de formação de capacitação popular. Almeja-se uma educação capaz de contribuir para a formação de homens e mulheres dotados de consciência social e de responsabilidade histórica, aptos para a intervenção coletiva organizada sobre a realidade, a partir de sua comunidade local, sempre em busca da melhoria da qualidade de vida para todos.

Esta educação implica, portanto, um caminho que parte da leitura da realidade, dos temas sociais de abrangência e urgência nacional e dos temas de interesse local. Para o estudo destes temas, faz-se necessário buscar recursos científicos. Daí a importância das áreas disciplinares concebidas como meios para o estudo e intervenção sobre a realidade. De acordo com Arroyo

Coletivos de docentes-educadores/as inventam formas de sair da rigidez das disciplinas e trazer esses conhecimentos de resistências para fortalecer os educandos em seu direito à vida e em suas resistências por libertação. A procura da escola, desde crianças, e da

RC: 89108

Disponível em: https://www.nucleodoconhecimento.com.br/educacao/libertadora-e-reflexiva 
EJA, como adolescentes, jovens, adultos em vidas tão violentadas pelos medos, será mais do que uma mostra de coragem para superálos. Poderá ser o espaço, o tempo de garantir seu direito a conhecimentos que valorizem suas resistências por libertação. Garantir um conhecimento que os liberte. Em coletivos de mestres e educandos podem ser levantados dados sobre a diversidade de formas de resistências e de tentativas de políticas do Estado pelo direito à vida. Entender as causas trazidas para justificar a violência, o extermínio da juventude popular, pobre, negra. A escola, o conhecimento escolar será o lugar onde poderão entender de maneira sistematizada porque são vítimas de tantas violências sociais e raciais, de gênero. Por que condenados a viver no medo (ARROYO, 2017, p. 244).

Por isso, a ação só se torna consciente e participativa, quando os excluídos sociais são capazes de compreender a sua própria historicidade, a sua própria identidade. Para este educando, de nada vale saber ler e escrever, se a sua realidade histórica permanecer inalterada. Então, de acordo com Arroyo (2017) para se reinventar a EJA é preciso fazer uma relação entre direitos humanos e educação de jovens-adultos com o intuito de reconhecer esses educandos como sujeitos de direitos humanos e alargar a concepção de educação na perspectiva da Constituição Federal e da LDB. Como consequência, também não reduzimos a educação à simplificada e reducionista visão de assegurar o ensino como algo que não puderam efetuar na idade regular.

Desta forma, não cabe ao professor depositar conteúdos, mas estar atuante como um sujeito histórico comprometido com a sua própria prática social. Como nos diz Freire

O papel ativo do homem em sua e com sua realidade. O sentido de mediação que tem a natureza para as relações e comunicação dos homens. A cultura como o acrescentamento que o homem faz ao mundo que não fez. A cultura como resultado de seu trabalho. Do seu esforço criador e recriador. O sentido transcendental de suas relações. A dimensão humanista da cultura. A cultura como aquisição sistemática da experiência humana. Como uma incorporação, por isso crítica e criadora, e não como uma justaposição de informes ou prescrições "doadas". A democratização da cultura - dimensão da democratização fundamental. O aprendizado da escrita e da leitura como uma chave com que o analfabeto iniciaria a sua introdução no mundo da comunicação escrita. O homem, afinal, no mundo e com o mundo. O seu papel de sujeito e não de mero e permanente objeto. A partir daí, o analfabeto começaria a operação de mudança de suas

RC: 89108

Disponível em: https://www.nucleodoconhecimento.com.br/educacao/libertadora-e-reflexiva 
atitudes anteriores. Descobrir-se-ia, criticamente, como fazedor desse mundo da cultura (FREIRE, 2019b, p. 142-143).

Na forma de trabalho de Paulo Freire, podemos observar que, primeiramente, para se educar adultos, é necessário fazer com que o aluno perceba sua própria existência, seu lugar neste mundo, exerça uma função. É importante recuperar sua estima, ou ajudar a construi-la. Quando este aluno é capaz de perceber estes detalhes ele começa a sentir a necessidade e o prazer de aprender, começa então uma nova etapa, na qual o aluno já possui vontade de aprender e busca o aprendizado. Desta forma é possível, segundo experiências feitas por Paulo Freire, se obter melhores resultados na alfabetização, que ele considera não só o saber ler e escrever, mas também a participação política.

Segundo Gadotti e Romão (2011), o estudante adulto não dever ser tratado como uma criança, pois este quer ver alguma aplicação no que está aprendendo. Paralelamente a isto, ele se sente de alguma forma temeroso, necessitando da criação de uma autoestima para que possa superar suas experiências frustradas da infância em relação à escola. $\mathrm{O}$ estudante adulto precisa, em primeiro lugar, ter o direito de se expressar.

A pedagogia da liberdade está diretamente ligada ao direito à educação como forma de sanar suas dificuldades. A educação atua como libertadora, pois tira o aluno da escuridão e o torna um ser mais crítico e atuante, traz novas perspectivas e desafios em busca de uma vida digna. A pedagogia da liberdade atua de forma direta na relação com o saber. A atual situação desses jovens e adultos pode ser mudada com a prática do conhecimento e do pensar.

O conhecimento escolar será libertador se, de um lado, revelar, aprofundar e desconstruir as causas estruturantes da história de sua segregação, repressão, extermínio: desvendar o racismo, o sexismo, o machismo, o patriarcalismo. Que entendam seu caráter de classe estruturante da violência e extermínio de adolescentes, jovens, de meninas, mulheres, preferencialmente negros, negras. Como avançar desvendando esses eixos estruturantes dos padrões de trabalho, de

RC: 89108

Disponível em: https://www.nucleodoconhecimento.com.br/educacao/libertadora-e-reflexiva 
expropriação do espaço, da moradia, da terra, dos direitos humanos mais básicos? A função da escola não será tanto educar para a tolerância de gênero, raça, com conselhos impregnados de moralismo. O que esperam do conhecimento escolar é entender o sexismo e o racismo que os violentam como estruturantes dos padrões capitalistas de expropriação dos direitos humanos mais básicos: o direito à vida. Aprofundar temas de estudo como o racismo e o sexismo mostrados nos mapas da violência são por si mesmos temas violentos. Inhumanos. Mostrar como se reforçam estruturando nossas instituições: o poder, a justiça-injusta, o trabalho, a expropriação da renda, da terra, da moradia. Da escola, universidade. Faltam esses conhecimentos aprofundados nos currículos da educação básica e superior. As vítimas, sobretudo, têm direito a conhecer quais estruturas que as vitimam. Têm direito a um conhecimento libertador (ARROYO, 2017, p. 246).

A Educação de Jovens e Adultos pode libertar e transformar os educandos em agentes da sociedade, pois a educação é a maior libertadora da humanidade. Gadotti e Romão (2011) nos diz que os jovens e adultos trabalhadores buscam superar suas condições precárias de vida através da luta. Essas condições precárias fazem parte da raiz do analfabetismo, já que estas comprometem o processo de alfabetização, principalmente, dos jovens e adultos.

Assim, devemos aos poucos tentar tornar a escola um ambiente de conhecimento e saber, de convivência e companheirismo, de liberdade e humanidade. Os estudantes trazem suas histórias, suas angústias e isto deve ser respeitado e aproveitado. Só assim conseguiremos tornar a EJA uma educação capaz de libertar das amarras sociais e da exclusão, transformando a perspectiva futura desses estudantes.

\section{CONSIDERAÇÕES FINAIS}

Diante do que foi pesquisado, podemos concluir que o processo de ensino e aprendizagem da EJA precisa ser construtivo, capaz de superar as metodologias dos livros didáticos tradicionais que, muitas vezes, pautam-se apenas na reprodução de conteúdos. Espera-se uma metodologia em que o educando seja um sujeito interativo

RC: 89108

Disponível em: https://www.nucleodoconhecimento.com.br/educacao/libertadora-e-reflexiva 
que pensa, pergunta, que é capaz de construir e reconstruir hipóteses enquanto estuda.

Percebemos que não é tarefa fácil conquistar a autonomia. Aprendemos a ser livres lentamente, superando nosso egoísmo e comodismo, de forma que, a partir da adolescência, o ser humano se encontra mais próximo do exercício pleno da liberdade. Muitas são as dificuldades diante de uma proposta coerente de educação para a liberdade.

Essa modalidade de educação popular, muitas vezes é tratada com preconceito por uma parcela da população, pois esses alunos advêm de classes de ensino regular e, por vários motivos, não conseguiram concluir seus estudos na época certa, condizente com suas idades. Nesse contexto, a educação popular torna-se uma espécie de resistência ao processo discriminatório perante as suas realidades.

A Educação de Jovens e Adultos é na verdade uma grande classe trabalhadora que, por diversos motivos, principalmente o econômico, os traz de volta para a sala de aula, diante de inúmeras dificuldades familiares, econômicas e sociais que eles necessitam superar para que tenham sucesso e êxito em sua trajetória educacional.

Pensamos que criar novos paradigmas para a Educação de Jovens e Adultos seja mais adequado, pois essa modalidade, na maioria das vezes, é deixada de lado por tratar de pessoas adultas e que são, em grande parte, não alfabetizadas ou alfabetizadas parcialmente.

Concluímos que a EJA não pode ser de alguma forma ignorada do processo educacional. Faz-se necessário a implementação de políticas capazes de resgatar esses alunos muitas vezes evadidos das escolas públicas voltadas para o ensino da EJA, uma vez que esta modalidade, acima de tudo, trata-se de um resgate social.

RC: 89108

Disponível em: https://www.nucleodoconhecimento.com.br/educacao/libertadora-e-reflexiva 


\section{REFERÊNCIAS}

ARROYO, Miguel G. Passageiros da noite: do trabalho para a EJA: itinerários pelo direito a uma vida justa. Rio de Janeiro: Vozes, 2017.

FREIRE, Paulo. Pedagogia da Autonomia: saberes necessários à prática educativa. Rio de Janeiro/São Paulo: Paz e Terra, 2019a.

. Educação como prática da liberdade. Rio de Janeiro/São Paulo: Paz e Terra, 2019b.

. Pedagogia da Esperança: um reencontro com a Pedagogia do Oprimido. Rio de Janeiro/São Paulo: Paz e Terra, 2019c.

Pedagogia do Oprimido. Rio de Janeiro/São Paulo: Paz e Terra, 2019d.

GADOTTI, Moacir; ROMÃO, José E. (Orgs.). Educação de Jovens e Adultos: teoria, prática e proposta. São Paulo: Cortez, 2011.

Enviado: Maio, 2021.

Aprovado: Junho, 2021.

RC: 89108

Disponível em: https://www.nucleodoconhecimento.com.br/educacao/libertadora-e-reflexiva 